\title{
EDITORIAL
}

\section{Crisis económica y derechos sociales irreductibles. Valor de la dignidad humana como criterio para los derechos sociales}

\section{Consejo de Redacción}

Resumen: En las últimas décadas la globalización ha aumentado el foso entre la riqueza y la pobreza, situación que se ha agudizado en detrimento de los más desfavorecidos debido a la crisis económica y social lo que ha llevado a que el modelo de economía social de mercado está seriamente amenazado. Ante esto, es preciso recuperar la concepción del Estado como Estado social y de justicia, lo que hace necesario establecer unos mínimos en los que la presencia del Estado debería asegurar ese ideal de justicia. Junto a ello, es preciso sentar los criterios que permitan establecer y ordenar las prioridades sociales en materia de bienestar; trazar la frontera entre lo esencial y lo accesorio, entre lo imprescindible y lo prescindible en el campo de las conquistas sociales. En este editorial, después de analizar las bases históricas del Estado social como punto de partida necesario para conocer la plasmación de los derechos sociales en el plano jurídico e institucional, nos planteamos si el reconocimiento y la garantía jurídica de los derechos sociales pueden estar por encima de toda coyuntura política y económica, pues en la actualidad parece que estamos asistiendo a un desmantelamiento del Estado social como consecuencia de la crisis. La respuesta a esta cuestión nos lleva a una posible redefinición de los derechos sociales protegibles por el Estado y a establecer cuáles pueden ser las posibles claves para fijar un "mínimo social irrenunciable".

Palabras clave: Estado social, derechos sociales, justicia social, crisis económica.

Fecha de aprobación: 6 de septiembre de 2013 
Economic crisis and irreducible social rights. Criteria for management policy on cutbacks

\begin{abstract}
In recent decades, globalization has widened the gap between wealth and poverty, a situation that has worsened the plight of the most poverty stricken due to the economic and social crisis which has seriously threatened the social economic model of the market. Given this, it is necessary to recover the concept of the state as a Social State and one of justice, which means establishing some minimum criteria in which the presence of the State should ensure that ideal of justice. Along with this, it is necessary to establish criteria to allow the establishment and management of social priorities in matters pertaining to welfare; to draw the line between what is essential and secondary, indispensable and dispensable in the field of social achievements. After analyzing the historical foundations of the welfare state as a necessary starting point to learn about the framework of social rights at legal and institutional levels, this editorial considers whether the legal recognition and guarantee of social rights can be placed above the whole political and economic climate, since currently it seems that we are witnessing a dismantling of the welfare state as a result of the crisis. The answer to this question leads us to a possible redefinition of the social rights to be protected by the State and to establish what might be the possible keys to setting an "indispensible social minimum".
\end{abstract}

Keywords: social status, social rights, social justice, economic crisis.

\section{La crise économique et les droits sociaux irréductibles. Critères de la politique de gestion sur les compressions}

Résumé: La globalisation a augmenté le fossé entre la richesse et la pauvreté durant ces dernières décennies et cette situation s'est accentuée au détriment des plus défavorisés à cause de la crise économique et sociale et rend le modèle d'économie sociale du marché très sérieusement menacé. Il faut donc récupérer la conception d'État comme Etat social et de justice ce qui requiert un minimum en ce qui concerne la présence de l'Etat et où l'État devrait assurer cet idéal de justice. Il est également indispensable de fixer les critères qui permettront d'établir et d'ordonner les priorités sociales en matière de bien-être ; de tracer les frontières entre l'essentiel et le secondaire, entrel'indispensable et le superflu dans le domaine des conquêtes sociales. Dans cet éditorial, après avoir analysé les bases historiques de l'État social comme point de départ nécessaire pour connaître la mise en œuvre des droits sociaux sur le plan juridique et institutionnel, nous nous demandons si la reconnaissance et la garantie juridique des droits sociaux peuvent être au dessus de toute conjoncture politique et économique car nous assistons actuellement à un démantèlement de l'État social dû à la crise. La réponse à cette question nous conduit à une redéfinition possible des droits sociaux et qui seraient protégés par l'État et à établir ce qui pourraient être les clefs pour fixer un minimum social irrévocable.

Mots clefs: État social, droits sociaux, justice sociale, crise économique. 


\section{Introducción}

Todo apunta a que nos enfrentamos al fin de un ciclo histórico. Los últimos seis años de crisis arrojan unos datos económicos ciertamente preocupantes, con una dramática cifra de paro que ha instalado en la frustración a varias de las generaciones de jóvenes mejor preparadas de la historia de este país. La política de contención del déficit y los recortes en el gasto público adoptados en los últimos años ahogan las esperanzas de muchas otras capas de la sociedad.

En las últimas décadas, la globalización -pese a tener aspectos positivos- ha aumentado el foso entre la riqueza y la pobreza. Una situación injusta que la crisis económica y social ha agudizado en perjuicio de los más débiles, de los marginados y de los excluidos, a escala mundial y en el interior de nuestras sociedades: como consecuencia de todo ello -y es en lo que estamos en España y en toda la Unión Europea- el modelo de economía social de mercado está seriamente amenazado.

Ante esta situación, recientemente denunciada en la declaración que el pasado mes de julio hizo pública UNIJES "Por la regeneración democrática de la vida pública en España" (http://www.unijes.net/forum-unijes-por-la-regeneraciondemocratica-de-la-vida-publica-en-espana), es urgente recuperar para la vida pública el conjunto de principios que reivindican el papel capital de la política en la creación de un espacio de libertad comprometido con los valores de la libertad, la igualdad y la solidaridad. El Estado social no puede perder su condición de Estado de justicia, porque la justicia -y la justicia social muy especialmente- es el eje conformador de lo entitativo del Estado. Esta concepción del Estado, que luce en nuestra vigente Constitución, se encuentra hoy profundamente amenazada en un contexto, además, en el que se están redefiniendo profundamente las relaciones entre el Estado y la sociedad. El reto hoy es señalar una línea roja de mínimos en la que la presencia del Estado debería asegurar ese ideal de justicia. Junto a ello, es preciso sentar los criterios que permitan establecer y ordenar las prioridades sociales en materia de bienestar; trazar la frontera entre lo esencial y lo accesorio, entre lo imprescindible y lo prescindible en el campo de las conquistas sociales. 


\section{El reconocimiento de los derechos sociales en el marco del Estado social}

\section{I. Bases históricas y teóricas del Estado social}

El constitucionalismo liberal decimonónico partía de una ideología no intervencionista del Estado sobre la sociedad, neutral en lo económico -en la clásica formulación de Adam Smith-, que abonó el terreno de la revolución industrial y de la radical transformación del contexto socioeconómico continental durante el siglo XIX. Los efectos desigualitarios y desequilibrantes de este modelo de crecimiento están en la base de las reivindicaciones sociales y políticas de la Europa de finales del siglo XIX y de principios del siglo XX.

En el primer tercio del siglo XX confluyen una serie de factores que concitan una profunda reconversión del papel del Estado y de la concepción de las relaciones entre éste y la sociedad: el auge del movimiento obrero revolucionario y el fortalecimiento del sindicalismo, el malestar social creado por la profunda crisis de 1929, las distintas corrientes políticas que cuestionan los principios del liberalismo y su más exacerbados efectos, o la consolidación de la doctrina social de la lglesia; que acabaron alentando los postulados ideológicos de una mayor implicación o responsabilidad social del Estado. En este contexto Hermann Heller acuña la expresión "Estado social"1 basado en los principios de igualdad, solidaridad y justicia social, que se erigen en el fundamento de las bases económicas, políticas y sociales del Estado.

La superación de la estructura decimonónica del Estado con la consolidación del Estado social de Derecho, anticipada en Alemania por la Constitución de la República de Weimar de 1919 y generalizada después de la segunda Guerra mundial en el constitucionalismo europeo (empezando por la Constitución alemana de 1949, donde la fórmula del "Estado Social de Derecho" se hace explícita y gana en consistencia y densidad política y jurídica), supuso un cambio sustancial en las relaciones entre los ciudadanos y los poderes públicos².

\footnotetext{
1 En su artículo "Rechtsstaat oder Diktatur?", aparecido en 1929 y recogido en su obra compilatoria en castellano Escritos políticos, Alianza, Madrid, 1985 y que también tiene reflejo en su Teoría del Estado, México, 1961.

${ }^{2}$ Cfr. Abendroth, Forsthoff yDoehring, El Estado social, Centro de Estudios Constitucionales, Madrid, 1986.
} 
Antes incluso de que la fórmula del Estado social cristalizase en la Ley fundamental alemana ya se había abierto camino otra expresión cercana: la del Estado de Bienestar o WelfareState, que tiene su origen en el pensamiento fabianista de los esposos Webb y que habría de encontrar en Keynes -en el orden del pensamiento-y en Beveridge -en el ámbito de la acción política- sus más altos exponentes. Esto último no es de extrañar, porque precisamente había sido en el Reino Unido donde mucho antes se habían ensayado un sistema de protección social basado en las poorlaws (leyes de los pobres) que hunde sus orígenes en el siglo XVII. Y, ya en el siglo XX, la creación del partido laborista impulsó en el plano parlamentario la programación de todo un sistema asistencial que tuvo como pilares las Leyes de 1908 de asistencia a ancianos y la de 1911 de atención de enfermos y parados (de ahí surgió la conocida expresión de Lloyd George de que el Estado socorría y prestaba protección al individuo "desde la cuna a la tumba"). Una serie de medidas ulteriores subsiguientes a la primera Guerra Mundial y a la depresión de 1929 vinieron a completar el sistema. Pero el gran salto cualitativo en el Reino Unido se da con la aprobación y puesta en práctica del Plan Beveridge que da carta de naturaleza al WelfareState como versión británica del Estado social.

El incremento de la acción del Estado en el campo social dio pie a un tercer concepto de resonancias religiosas: el "Estado providencia", fórmula que califica el papel que corresponde al Estado en proveer las necesidades y los cuidados necesarios de los ciudadanos. La acogida de esta expresión puede considerarse la más extendida, llegando a calar incluso en la fórmula Rooselveltiana del New Deal. Y aún había de nacer una última denominación cargada de expresividad: la del Estado de la procura asistencial o de la deseingvorsorge; idea con la que se quiere definir al Estado encargado de procurar al hombre cuanto necesita para su existencia y para luchas contra la inestabilidad de su existencia.

Así, pues, Estado social, Estado del bienestar, Estado providencia y Estado de la procura existencial son distintos modos de identificar y definir una específica respuesta política, económica y jurídica contra las desigualdades sociales, respuesta que necesariamente pasa por el aumento de la intervención socioeconómica del Estado y la transformación radical del modelo liberal de Administración pública.

Formulada así la idea del Estado social su expansión ha sido extraordinaria en el constitucionalismo occidental de la segunda mitad de siglo XX. Como ha explicado Rosanvallon ${ }^{3}$, su desarrollo se ha sustentado, en lo económico, sobre lo que el

${ }^{3}$ La crise de l'État providence, París 1981. 
mencionado autor ha denominado "los auspicios de la ecuación keynesiana", es decir, el principio de la correspondencia global entre los imperativos del crecimiento económico y las exigencias de una mayor equidad social, sin perder de vista la máxima del pensamiento de Keynes: una socialización suficientemente amplia de la inversión se acreditará como el único medio que asegure aproximadamente el pleno empleo.

Mientras que en el Estado liberal, comprometido en el mantenimiento de la seguridad interior y exterior, los ciudadanos mantenían un mínimo contacto con el poder, la situación es radicalmente contraria en el Estado social. Éste como señala Ernst Forsthoff, uno de sus más cualificados teóricos, a diferencia del Estado liberal de Derecho, es un Estado que garantiza la subsistencia (se responsabiliza de la «procura existencial») y, por tanto, es Estado de prestación y de redistribución de riqueza. El hombre moderno no solamente vive en el Estado, sino del Estado, de lo que éste le procura. La pérdida del espacio vital dominado por el individuo y la de las reservas existenciales que éste conlleva, entregan a aquél en manos del Estado. Se siente en dependencia respecto del Estado y traslada a él la exigencia de seguridad y la garantía de su existencia, a las que no puede hacer frente desde la inestabilidad de su ámbito personal, de alcance limitado y reducido, esencialmente condicionado por las circunstancias azarosas del lugar y el estrato social en el que cada persona nace y se ubica.

Desde mediados del siglo XX los Estados democráticos y sociales de Derecho propugnan unos mínimos sociales que, junto a los derechos de libertad generalizadamente reconocidos desde la revolución francesa, pertenecen a todos por razones de justicia social, solidaridad y de igualdad material. La constitucionalización del Estado social asienta en el plano formal e institucional del modelo de Estado la aspiración humana del bienestar colectivo y, por tanto, de la solidaridad. Propósito que cristaliza en el reconocimiento de un conjunto de derechos sociales y en la proclamación de obligaciones positivas del Estado para lograr su consecución efectiva.

El postulado del Estado social es garantizar las necesidades básicas que permiten el desarrollo de la personalidad y de la dignidad de cada persona, que no deben quedar al albur de la condición personal de cada cual, de su situación económica ni de factores territoriales o de cualquier otra índole que hagan para ella inalcanzable el ideal de la felicidad. Estos derechos sociales resultan indisponibles tanto para el Estado como para el mercado. Dado que el segundo no los proporciona de modo accesible ni con carácter universal a todos los ciudadanos, es el primero, el Estado, quien ha de procurar su plena satisfacción. El Estado Social busca así 
garantizar desde la acción de los poderes públicos unos niveles mínimos de empleo, de salario, de alimentación, de acceso a la salud, a la vivienda, a la educación, de acceso un sistema de pensiones, etc.; aspira en suma a dispensar directamente prestaciones sociales básicas y hasta culturales y de ocio.

Por lo demás, los derechos sociales no se oponen a los derechos de libertad, sino que constituyen su natural correlato cuando la libertad se concibe no sólo en su dimensión negativa, como no intromisión, sino también en su faceta positiva, como poder; lo que permite al Estado imponer determinadas condiciones de redistribución de la riqueza, mediante un sistema tributario basado en la imposición directa y progresiva en razón de los niveles de renta de cada ciudadano y transformar la orientación social del capital y de la propiedad predicando la función social de ésta y arbitrando mecanismos de intervención efectiva del Estado en el mercado para corregir los desequilibrios que éste naturalmente produce.

El papel del mercado como instrumento de generación y asignación de recursos se concilia con el papel económico, político y social del Estado como redistribuidor de recursos. Junto a ello, el Estado asume ciertos medios de producción mediante la creación de monopolios públicos de gestión sobre recursos esenciales, lo que da pie a la creación de una técnica jurídica enormemente floreciente en la segunda mitad del siglo XX: el servicio público, con una capacidad de transformación social hasta entonces desconocida.

La finalidad del Estado social, pudiera decirse en fin, no es sino la mejora de las condiciones de vida de los ciudadanos. El Estado asume la dirección y la organización de la sociedad. Se difumina la distinción entre Estado y sociedad lo que impone que el Estado y la sociedad acaben por ser esencialmente una misma cosa, en la célebre imagen de Carl Schmitt.

\subsection{La plasmación de los derechos sociales en el plano jurídico e institucional}

En el marco internacional, el siglo XX ha conocido la proliferación de múltiples declaraciones universales de derechos sociales, o de ámbito comunitario europeo; tanto de orden general (como la Carta social Europea de 1961 -revisada en Estrasburgo 1996- o la Carta de los derechos fundamentales de la Unión Europea -Niza 2000-, incorporada al Tratado de Funcionamiento de la UE-Lisboa 2007-), como de tipo sectorial (como la Carta comunitaria de los derechos sociales fundamentales de los trabajadores -Bruselas 1989-, la Declaración Universal sobre 
bioética y Derechos Humanos -Oviedo 2005-, la Convención internacional de los derechos de las personas con discapacidad -Nueva York, 2006-, que se han unido en los últimos tiempos a una larga lista sobre las más variadas materias: infancia, género, salud mental, etc.).

En el plano interno del Estado español, el constituyente de 1978, que define en el primero de sus artículos a España como "un Estado social y democrático de Derecho", consciente de la dificultad de garantizar la eficacia jurídica de los derechos sociales de prestación, optó por configurarlos como misiones o deberes genéricos del Estado, enunciándolos como simples "principios rectores de la política social y económica" (Capítulo III del Título I de la Constitución) y no como derechos subjetivos directamente accionables ante los Tribunales que, no obstante, "informan la legislación positiva, la práctica judicial y la actuación de los poderes públicos" (como precisa el artículo 53.3 CE).

En cumplimiento de ese mandato, el legislador ha desarrollado y perfeccionado ampliamente muchos de esos derechos que, hace treinta y cinco años, eran poco más que meras aspiraciones pero que hoy son derechos jurídicamente exigibles (como el derecho a una vivienda digna, el acceso de la mujer al trabajo en condiciones de igualdad, la protección integral de los discapacitados, la defensa de los consumidores o el amplio espectro de derechos medioambientales que la legislación consagra); al tiempo que ha definido otros cuya garantía por el Estado parecía entonces una quimera irrealizable (el acceso gratuito a todos los tramos educativos, las prestaciones sanitarias avanzadas, el sistema de pensiones no contributivas, el acceso a las tecnologías de la comunicaciones en condiciones de universalidad y precio razonable etc.).

Por su parte, las Comunidades Autónomas han avanzado en esta línea hasta extremos que hace una generación eran inimaginables. Particularmente, los Estatutos de Autonomía reformados en el bienio 2006-2007 (Valencia, Cataluña, Andalucía, Baleares, Aragón, Castilla y León y Extremadura) han multiplicado vigorosamente el número y la extensión de los derechos sociales que reconocen, que en muchas ocasiones no son sino trasunto de los que los legisladores autonómicos habían plasmado en las leyes aprobadas en ejercicio de sus competencias y que expresan, como gráficamente ha dicho Bastida Freijedo el "alma constitucional" de las autonomías ${ }^{4}$.

\footnotetext{
4 "Autonomía política, soberanía y declaración estatutaria de derechos", El Cronista del Estado Social y Democrático de Derecho, núm. 35, 2013.
} 
Por lo demás, no hay que desdeñar el dato, nada baladí, de que esos Estatutos de Autonomía reformados se aprueban justo antes de que se desate la crisis económica que hoy nos asola y, por tanto, nacen en un contexto económico de opulencia.

Pese a las limitaciones que el Tribunal Constitucional ha dado a las declaraciones de derechos sociales que contienen esos Estatutos, rebajando notablemente su valor y eficacia jurídica y dejándolas en meras aspiraciones programáticas -simples mandatos al legislador- (otra cosa escapa -según el Tribunal Constitucional- a las posibilidades normativas de un Estatuto de Autonomía, como sostuvieron las Sentencias 247/2007 y $31 / 2010$ referidas, respectivamente, a los Estatutos valenciano y catalán), no puede negarse que las Comunidades Autónomas han sido en las dos últimas décadas una fuente de autocrecimiento expansivo de generación de políticas de bienestar social.

Este crecimiento de los derechos sociales en el plano autonómico -más local- ha generado a pequeña escala un consenso vital sobre los parámetros de bienestar que debe proporcionar el aparato de lo público que contrasta enormemente con la percepción que de ese nivel de bienestar se tiene en otros territorios o en otros Estados. Basta con leer los Capítulos Il y III del Título I del Estatuto de Autonomía para Andalucía -por ejemplo-y enfrentarlo con la Carta de Derechos Fundamentales de la Unión Europea de 2007. Mientras que las aspiraciones al bienestar colectivo en la última de las declaraciones citadas se limitan a un mínimo común denominador de los derechos sociales que reconocen las Constituciones de los Estados miembros de la Unión Europea (derecho al trabajo, a la salud y seguridad en el mismo y al subsidio de desempleo y demás prestaciones que derivan de la cotización; a la protección de la maternidad y la paternidad y otras condiciones de trabajo justas y equitativas; derecho a la gratuidad de la educación obligatoria; a la protección y bienestar de los menores y de los mayores; a integración de los discapacitados; el derecho de acceso a los servicios públicos; todo lo cual se reconoce, por regla general "en las condiciones establecidas por las legislaciones y prácticas nacionales"); los derechos recogidos en citado Estatuto andaluz -que no difieren en esencia de los que reconoce el valenciano o el catalán, igualmente reformados- tienen un mayor alcance en número y en la cualidad de las prestaciones sociales que se les asocian. Así, por ejemplo, los citados Capítulos del Estatuto andaluz consagran derechos sociales muy avanzados, como el derecho universal a una renta básica; el derecho de acceso gratuito a los servicios de empleo; el acceso a una vivienda de promoción pública; la cobertura integral a las personas dependientes; el acceso a los cuidados paliativos; a las terapias del dolor y la dignificación del proceso de la muerte; el derecho al consejo genético; la gratuidad de los libros de texto en la enseñanza obligatoria; el derecho de acceso a la sociedad del conocimiento y 
a las nuevas tecnologías; el derecho a la protección de la diversidad biológica, de los procesos ecológicos y el patrimonio natural; el derecho al "envejecimiento activo"; la atención social a personas que sufran marginación, pobreza o exclusión y discriminación social, así como la integración laboral, económica, social y cultural de los inmigrantes; el derecho de acceso a unos servicios públicos de calidad en condiciones de gratuidad para los más desfavorecidos, etc.

La inmensa mayoría de estos derechos sociales conllevan una acción positiva por parte de los poderes públicos que, evidentemente, compromete real o potencialmente grandes partidas del gasto presupuestario. Por ello, uno de los debates más intensos desatados en el contexto de la crisis económica que vivimos es el de la redefinición de los derechos sociales y de su garantía, ambas menguantes. El debate ha conmovido las bases de la doctrina del Estado social en toda su extensión, puesto que no sólo cuestiona el alcance de esos derechos y de la forma en que pueden alcanzarse las prestaciones que la legislación consagra; sino que parece demandar un replanteamiento del modelo mismo.

\section{El desmantelamiento del Estado social en tiempos de crisis. ¿Puede situarse el reconocimiento y la garantía jurídica de los derechos sociales por encima de toda coyuntura política y económica?}

A finales de la década de los ochenta del siglo pasado comenzó a hacerse patente una seria "crisis" del Estado social que se ha acelerado enormemente en el contexto de la actual crisis financiera.

Los presupuestos más notables del cuestionamiento del Estado social se sitúan comúnmente en el crecimiento y densificación del aparato del Estado y en la multiplicación de sus funciones para la realización de prestaciones sociales desde el ámbito de lo público. Los factores que determinan ese engrosamiento del Estado son conocidos, $y$, entre otros, responden a estas circunstancias: a) la estatificación de actividades privadas preexistentes y la asunción de nuevas actividades y funciones a cargo del Estado; b) la multiplicación de las estructuras administrativas y del empleo público, con el consiguiente incremento de la burocracia; todo ello multiplicado y replicado por la emergencia de las Comunidades Autónomas; c) un colosal incremento del gasto público; d) el detraimiento creciente de los recursos económicos por la vía de la fiscalidad o la parafiscalidad; y e) la extensión de la atonía y la actitud pasiva en una ciudadanía cada vez más acostumbrada a cultivar la mentalidad asistencial o subsidiada. 
Las causas de la crisis del Estado social son, pues, de signo variado, aunque todos los análisis coinciden en apuntar que la principal de todas es el insoportable incremento del gasto público que, tras la crisis económica del petróleo a finales de los setenta del siglo XX, puso en cuestión el modelo keynesiano de crecimiento económico en ciclos progresivos al alza (con épocas de ralentización o cierta regresión seguidas de impulsos siempre ascendentes). Algún dato significativo puede servir para ilustrar la crisis referida: a finales del pasado siglo, los gastos de la Seguridad Social suponían una tercera parte del presupuesto nacional; en la Europa continental, el gasto público rondaba el 50\% del PIB; en España, el gasto de las prestaciones sociales aumentó en 2,7 billones de pesetas entre 1988 y 1993 y a finales de la década suponían más de un $60 \%$ del déficit público.

Algo más de una década más tarde, y tras seis años de depresión económica en el ámbito europeo, los datos que se manejan a mediados de 2013 para justificar la reforma del Estado y del sistema de Administraciones públicas en España son demoledores ${ }^{5}$. El indicador utilizado para medir el peso del Estado en la economía es el nivel de gasto no financiero sobre el Producto Interior Bruto (PIB). Ese indicador se eleva en España al $44 \%$, con un aumento del gasto público particularmente intenso en los últimos años. Entre 2005 y 2011 el gasto público incrementó su peso en el PIB en 6,8 puntos porcentuales. Frente a ello, la evolución de los ingresos públicos en España y en la zona euro entre 1995 y 2013 en porcentaje del PIB, según datos de la Comisión Europea, muestra una fuerte caída de los ingresos públicos en España, de modo que en 2012 el nivel de ingresos públicos se situó en el $36,4 \%$ del PIB, casi 10 puntos porcentuales de PIB por debajo de la media de la zona euro, siendo el país de la eurozona con el nivel más bajo de ingresos públicos sobre el PIB, solo por detrás de Irlanda $(34,6 \%)$ y de Eslovaquia $(33,1 \%)$. Dicho de otro modo, el enorme peso del sector público sobre la economía no se compadece en absoluto con la escasa capacidad de autofinanciación del modelo, y eso sin tener en cuenta el creciente incremento de la deuda financiera externa $y$ de sus intereses.

El tamaño de la Administración española en términos de empleados públicos ha experimentado en los últimos 10 años un fuerte crecimiento, siendo llamativo que, desde el comienzo de la crisis, entre el tercer trimestre de 2007 y el tercer trimestre de 2011 , el empleo público se incrementó en 288.700 empleados, según datos de la Encuesta de Población Activa. Sin embargo, tampoco ha de ocultarse que desde

\footnotetext{
${ }^{5}$ Informe de la Comisión para la Reforma de las Administraciones Públicas, hecho público a finales de junio de 2013 (http://www.seap.minhap.gob.es/dms/es/index/bannersTematicos/INFORME-LIBRO/ INFORME\%2OLIBRO.PDF).
} 
el tercer trimestre de 2011 hasta el primer trimestre de 2013, se ha producido una reducción del empleo público en 374.800 trabajadores. En este periodo, el empleo público ha caído un $11,6 \%$ frente al $7,7 \%$ en que ha disminuido la ocupación en el sector privado.

Si atendemos a la estructura del gasto, desde el punto de vista funcional, con datos extraídos de los Presupuestos para el ejercicio 2012, el gasto social y en servicios públicos básicos representó el 65,92\%, lo que representa cerca del 30\% del PIB, sin contar los intereses de la deuda. Y en cuanto al personal, en la Administración General del Estado y las Comunidades Autónomas sólo el 25\% de los empleados públicos se encuentran en las estructuras puramente administrativas, estando el resto dedicados a servicios de sanidad, educación, seguridad, defensa o justicia. Respecto a su distribución territorial, casi la mitad del gasto público está gestionado por las Comunidades Autónomas y la Administración local.

El proceso de descentralización ha producido un cambio en la distribución de los empleados públicos entre las Administraciones. De acuerdo con los datos del Registro Central de Personal, entre 1982 y 2012 los empleados de la Administración General del Estado se han reducido a cerca de la cuarta parte; los de las Comunidades Autónomas, prácticamente inexistentes en 1982, se han multiplicado por 30 y los de las entidades locales se han multiplicado casi por 4 .

La descentralización tanto del gasto como del empleo público que ha acompañado la atribución de competencias a las Comunidades Autónomas se ha producido de forma acelerada, lo que ha convertido a España en uno de los países con mayor grado de descentralización de gasto de la OCDE. En muchos casos dicho crecimiento ha respondido a la creación de estructuras administrativas en áreas cubiertas por la Administración estatal, lo que ha generado actuaciones redundantes de otras Administraciones Públicas.

Se trata, por lo demás, de un fenómeno de engrosamiento de la "cosa pública" común a los países descentralizados de la zona euro.

A la vista de esta realidad no es de extrañar el auge actual del modelo antagónico y de las corrientes revisionistas del pensamiento Keynesiano capitaneadas desde finales del siglo pasado por Friedman en lo económico y por Hayek en el campo de la ética política. Como tampoco es de extrañar que una de las primeras plasmaciones prácticas del llamado "neo-liberalismo" tuviera lugar en uno de los países de mayor tradición en la política de gasto social: el Reino Unido, que dio un giro ultraliberal bajo los auspicios de la política Thatcheriana. A partir de estas tendencias 
revisionistas, los efectos de la neo-liberalización se han extendido progresivamente por toda Europa, llegando a su momento álgido en el presente. Orquestada por el impulso de la Unión Europea y el peso de la Alemania de la Canciller Merkl, la reorientación del modelo del Estado social se ordena hoy nítidamente, entre otras fórmulas y medidas, al generalizado objetivo de privatización del sector público, de contención y reducción del déficit presupuestario y de los consiguientes recortes en el campo asistencial y de las prestaciones sociales.

No obstante, lo cierto es que la situación terminal alcanzada por el Estadoprovidencia no ha desembocado en el ámbito de la Unión Europea en una negación del modelo, sino en una reorientación del mismo que pretende limar sus deficiencias, mesurar sus negativas consecuencias en el terreno del gasto público, pero no abandonar lo que normalmente se califican como "conquistas sociales" del Estado.

En suma, la caracterización del Estado social en su faceta de interventor en la economía general, ha involucionado en los últimos años recortando sus funciones para restablecer una relación más libre entre economía y mercado propia de un sistema capitalista globalizado. Entra ahora en discusión la primacía del mercado sobre el Estado, lo que acentúa la función del mercado como principal vertebrador del crecimiento económico, en perjuicio del papel regulador del Estado. El mercado está recuperando a pasos agigantados las funciones que justificaron la aparición y expansión del Estado social.

En este contexto, la principal cuestión es qué hacer para preservar las conquistas sociales del Estado en un panorama de contención del déficit y del gasto público y ante una inercia irrefrenable de adelgazamiento del Estado y de la Administración. Cómo hacer posible, en suma, la pervivencia del Estado social; siquiera sea de un Estado "social" de mínimos.

\section{La redefinición de los derechos sociales protegibles por el Estado}

\section{I. El nuevo contexto de relaciones Estado-sociedad}

Desde la perspectiva del modelo de Estado, esa reorientación del modelo puede considerarse una apuesta genuinamente europea que viene siendo desarrollada 
desde hace algún tiempo en el campo de la economía, de la filosofía del Derecho, de la teoría del Estado y de la ética política. En el plano de la teoría del Estado es fundamental la referencia a autores como Nozick y Rawls, cuyo pensamiento es determinante para comprender a quienes hoy defienden en Europa una posición "alternativa" en lo político y lo económico, como Ralf Dahrendorf o Anthony Giddens (el teórico de la "tercera vía", cuyas ideas fructificaron parcialmente en la práctica bajo el Gobierno laborista de Tony Blair). En España, la tendencia no ha pasado desapercibida y se han producido síntesis importantes y aportaciones de relevancia en los campos de la economía, la ética y la ciencia política. Destacan, en este sentido, los trabajos de Juan Velarde ${ }^{6}$, Adela Cortina ${ }^{7}$ y, en el terreno del análisis, de Vicenç Navarro.

Estos autores han detectado con acierto los aspectos en los que entran en conflicto el Estado social o del Bienestar y las exigencias económicas internas (contención del déficit) y externas (apertura de los mercados y globalización financiera). Merece la pena enumerar algunos de los focos problemáticos que apuntan: $1^{\circ}$ ) La caída de los porcentajes de cobertura de las prestaciones del sistema de la Seguridad Social cuando este se financia a través de los recursos del propio sistema; es decir, de las cotizaciones sociales. $2^{\circ}$ ) La generalizada necesidad de restringir el gasto público. $3^{\circ}$ ) La financiación de la protección social y asistencial ha acabado siendo, en una gran cantidad de países, un instrumento al servicio de la mejora de la competitividad exterior por la vía de los costes. $4^{\circ}$ ) Constatación del final de las utopías, que se mezcla con un progreso notable de la corrupción política. $5^{\circ}$ ) En todas partes se predica que se apliquen al sector público, en aras a la eficacia, toda una serie de iniciativas que alzapriman el papel de la iniciativa privada. $6^{\circ}$ ) La urgente necesidad de reformar el panorama impositivo y contributivo relacionado con el Estado del Bienestar. $7^{\circ}$ ) El envejecimiento de la población en los países que disfrutan un Estado del Bienestar plantea unas cargas para los activos que cada día se rechazan socialmente con mayor vehemencia. $8^{\circ}$ ) Europa descuida la

6 "Consideraciones sobre el Estado del Bienestar", en El Estado del Bienestar posible, Madrid, 1994; y su obra junto Alejandro Cercas El Estado del bienestar, Madrid 1999, Acento.

${ }^{7}$ La obra de Adela Cortina en el campo de la ética política es extensa, pero acaso es posible destacar en el específico enfoque que nos ocupa su obra Ciudadanos del mundo: hacia una teoría de la ciudadanía, Alianza ${ }^{2} 1998$, en especial, en su capítulo referido a la "Ciudadanía social: del Estado de Bienestar al Estado de Justicia".

${ }^{8}$ Con dos monografías de referencia: Neoliberalismo y Estado del Bienestary Globalización económica, poder político y Estado del Bienestar. Asimismo es de resaltar su libro Bienestar insuficiente, democracia incompleta. Sobre lo que no se habla en nuestro país, Barcelona 2002, Anagrama. 
necesidad, no ya de armonizar $\mathrm{u}$ homogeneizar, sino ni siquiera de coordinar las diversas realidades nacionales en el terreno de la legislación social y asistencial. $\left.9^{\circ}\right)$ Las clases dominantes sacan mayor provecho de los servicios supuestamente "universales", lo cual se hace cada vez más evidente cuando el sistema de prestaciones sociales se confronta con las nuevas clases menesterosas que ha conformado la inmigración en Europa. $10^{\circ}$ ) El rédito político cortoplacista es una inercia desfavorable para afrontar medidas de igualdad material que beneficien a las minorías, cuando lo políticamente rentable es acordar medidas generales para la mayoría (entendiendo la igualdad en un sentido meramente formal), lo que impide discriminar las necesidades reales de quienes más necesitan.

Frente al pesimismo que subyace en este diagnóstico, algunos autores como Adela Cortina han avanzado una visión posibilista de corte más positivo. Tras analizar la etiología de la crisis del Estado del Bienestar y exponer con razones críticas las graves deficiencias del neoliberalismo exacerbado, la mencionada autora-miembro de este Consejo de Redacción- propone la búsqueda de un "nuevo equilibrio" superador. El presupuesto de partida es el generalizado convencimiento políitico y social de que "hay una dimensión del Estado del Bienestar que nadie está dispuesto a tirar por la borda". En este propósito, la autora considera necesario distinguir los conceptos de Estado Social, de un lado, y Estado del Bienestar, de otro; porque "aunque confundido en la práctica (...) urge diferenciarlos". La razón es que "si el Estado de Bienestar ha degenerado en megaestado y, por eso mismo, ha entrado en un proceso de descomposición, los mínimos de justicia que pretende defender el Estado Social de Derecho constituyen una exigencia ética que en modo alguno puede dejarse insatisfecha (...) sin que el Estado pierda su legitimidad". Los tres puntos principales que cabe extraer de la propuesta de Cortina son:

$\left.1^{\circ}\right)$ Reivindicar que la justicia es el fundamento del Estado social de Derecho, y que justicia no es necesariamente igual a bienestar (dicho de otro modo, que justicia social y solidaridad colectiva son conceptos diferentes en el orden cualitativo y cuantitativo de las prestaciones sociales).

$\left.2^{\circ}\right)$ Considerar que la protección de los derechos humanos de corte social no demanda una institucionalización de la solidaridad, sino de la justicia distributiva. La solidaridad es un valor ético ajeno al Estado porque pertenece a la esencia individual de cada uno. La justicia, no la solidaridad, es la que hace "real y efectiva" la libertad.

$\left.3^{\circ}\right)$ Reconocer que el antídoto del megaestado del Bienestar no es el Estado liberal, pues este modelo no se compadece con el del Estado social. La 
alternativa es el Estado social entendido como Estado de justicia. Ésta es la síntesis de un Estado cooperativo con la sociedad civil, donde lo que hay que institucionalizar son los mínimos de justicia, que no de bienestar.

Puede apreciarse que la redefinición del concepto de justicia como equidad (más que como solidaridad), que ya presidía el pensamiento de Rawls, es la palanca que retoma Cortina para calificar el Estado Social como Estado de Justicia, en el que la equidad y la igualdad no han de confundirse con la solidaridad "retributiva" que alimenta la mentalidad subsidiada o el cortoplacismo miope de los políticos que antes denunciábamos.

De este modo, en el campo de la ética política, la idea de justicia distributiva es considerada actualmente como la virtud cardinal que aúna los ideales de igualdad y de libertad. En este orden de consideraciones hay un "mínimo irrenunciable" de prestaciones y servicios sociales y culturales que el Estado tiene que garantizar, ya sea porque él mismo los gestione o ya porque facilite las condiciones y establezca los criterios para que el propio mercado y la sociedad civil abastezcan de los mismos a la ciudadanía en condiciones de universalidad, continuidad e igualdad. El problema es, en este sentido, identificar ese "mínimo irrenunciable" en el que se legitima el Estado social. Unos hablan de un "mínimo decente", otros de un "mínimo absoluto". A nuestro juicio, ese "mínimo" está representado-como veremos más adelante- en nuestra Constitución por los derechos y aspiraciones contempladas como "principios rectores de la política social y económica" (Capítulo III de su Título I), cuyo objeto no se fundamenta tanto en la idea de "bienestar" como en la justicia social.

Desde una perspectiva más realista, pues, este ideal de justicia distributiva como aspiración del Estado social debe redefinirse hoy coadyuvado con el complemento que aporta la idea de la solidaridad colectiva, que es cosa bien distinta -en los términos que ha argumentado Victoria Camps- a la solidaridad "caritativa".

Qué duda cabe que todas estas reflexiones están en la base de las tendencias que actualmente marcan el rumbo de lo público. La "retirada" del Estado del campo económico y el surgimiento de un nuevo modelo "regulatorio", los efectos de la "globalización" y las respuestas que comienzan a apuntarse desde los campos del Derecho Internacional Público y la Teoría del Estado para dotar de nuevos contenidos positivos a la soberanía, son-entre otros-fenómenos íntimamente asociados a los que aquí se han señalado desde la perspectiva del modelo de Estado.

${ }^{9}$ Virtudes públicas, Madrid 1990, Espasa Calpe, pp. 33 y ss. 
En este contexto cobra la máxima vigencia una reciente y muy sugerente reflexión del profesor Esteve Pardo en torno a las relaciones entre el Estado y la sociedad ${ }^{10}$. Para el citado profesor, esas relaciones se encuentran hoy ante una nueva clave en cuyo trasfondo se advierte un movimiento "de tipo tectónico" que fuerza la recomposición de dichas relaciones en el contexto de crisis económica, institucional y social que nos atenaza. Más allá de las cifras económicas, de la conflictividad social y la gravedad del paro, de la corrupción rampante, de la irracionalidad de las cargas públicas o de las limitaciones de los gobernantes; allá, en el trasfondo de la crisis, se advierte un corrimiento, una recomposición en profundidad de la relación entre Estado y sociedad que determina que muchos de los movimientos que percibimos en el escenario cotidiano sean resonancias de esa falla que se abre a una mayor profundidad y que encuentra su explicación de fondo en el desajuste entre el aparato y configuración del Estado y la sociedad actual, con su peculiar y compleja configuración. Todo indica que nos encontramos ante una nueva correlación entre Estado y sociedad que no está todavía ensamblada y que de esos desajustes derivan toda una serie de disfunciones que se encuentran entre los orígenes de la crisis.

Una nueva correlación que sucede a otras bien conocidas en Europa en los tres últimos siglos y que explican la formación de diferentes modelos de Estado e ilustran sobre el sentido de sus instituciones. Si el modelo de Estado liberal se construyó sobre la estricta separación entre Estado y sociedad, y el modelo del Estado social se levanta sobre la interconexión e integración de estas dos realidades, el modelo de Estado al que avanzamos no parece que pueda sostenerse sobre la postura preponderantemente activa del Estado y correlativamente pasiva de la sociedad que ha caracterizado el desarrollo del Estado social en nuestros días.

La singularidad de la transformación que ahora se atisba es que, a diferencia de las dos anteriores, no tiene en el Estado su protagonista activo, sino que viene impulsada por el extraordinario fortalecimiento de la sociedad en las últimas décadas. Este fenómeno de desajuste o desprendimiento - de falla tectónica por seguir con la metáfora de Esteve- tiene su matriz en el extraordinario fortalecimiento de la sociedad frente al Estado en términos de poder. Hoy es la sociedad, en su consideración universal o internacionalizada, la que activa mecanismos de decisión que amenazan las estructuras del Estado. En efecto, actualmente el poder ya no se localiza en el Estado, sino en su extrarradio. Es ahí donde mayormente se encuentran, entre otros, el poder económico y financiero, el poder que deriva del

${ }^{10}$ La nueva relación entre Estado y sociedad. Aproximación al trasfondo de la crisis, Madrid-Barcelona 2013, Marcial Pons.

Revista de Fomento Social 68 (2013) 
conocimiento científico y técnico, el poder que antes se sustentaba en la titularidad sobre servicios públicos dependientes del Estado, el poder sobre la comunicación y sus infraestructuras, etc.

Las profecías -dice agudamente Esteve- que en el siglo XX lanzaron las mentes más brillantes vaticinando una fusión entre la sociedad y el Estado bajo el dominio de este último han resultado así fallidas. Esa fusión no se ha producido, la integración o interacción entre ambas se resquebraja a pasos agigantados y, lo más destacable, la sociedad se ha fortalecido extraordinariamente hasta dominar esos y otros muchos espacios de poder. En muy buena medida se ha fortalecido porque ha sido capaz de organizarse y regularse eficazmente sin la tutela o dirección del Estado, de autorregularse en definitiva; de adoptar sus propios referentes normativos, ajenos al ordenamiento estatal, $y$ de establecer mecanismos decisorios que son los que realmente marcan la evolución del mercado global, de los flujos financieros y de la orientación y dominación misma de la ciencia y del conocimiento.

Los intereses de la sociedad así concebida no conocen fronteras ni obedecen a los parámetros geopolíticos del Estado, pero tienen un potencial capaz de zarandear los cimientos del Estado soberano, como la crisis financiera ha puesto de manifiesto. Así, por ejemplo, el gran público ha podido contemplar en directo cómo unas entidades privadas rodeadas de opacidad, las llamadas agencias de rating, emiten unas declaraciones que pueden hacer tambalear a los Estados y a sus dirigentes, condicionando su política económica presuntamente soberana y hacen visible así una realidad que atemoriza y es motivo de escándalo. Las decisiones sobre la investigación sanitaria o sobre el desarrollo de tecnologías más sostenibles no se toman hoy con criterios de necesidad sino de conveniencia económica, porque el poder decisorio no se ubica en el Estado sino fuera del mismo: en las grandes corporaciones multinacionales que marcan el rumbo del conocimiento con criterios puramente economicistas.

Hasta tal punto esto es así que, por primera vez, el Estado se siente amenazado por esos poderes externos y ahí se explica la reacción constitucional en la reforma más relevante y extensa de nuestra Constitución que cristaliza en su nuevo artículo 135 para establecer un sistema de contención del gasto público y del déficit en pro de la llamada "estabilidad presupuestaria". Una reacción inequívocamente defensiva ante una excesiva exposición a los mercados financieros que hace peligrar la sostenibilidad del Estado social, como explícitamente se reconoce en el texto de la reforma y la legislación de estabilidad presupuestaria que la desarrolla, resueltamente orientadas a limitar la exposición al crédito y a la deuda externa. 
Advierte Esteve así un fenómeno que se desarrolla en dos direcciones que, aunque opuestas, se cruzan y se relacionan estrechamente: por una parte, esa fortalecida sociedad que se autoorganiza y autorregula eficazmente está ganando espacios que se tenían como propios del Estado y bajo su dominio; por otra, el Estado está transfiriendo a la sociedad funciones hasta ahora bajo su responsabilidad y que se consideraban característicamente suyas. En este corrimiento de papeles, la sociedad está ganando espacios al Estado sin que éste pueda hacer nada para imponer a aquélla la defensa de los intereses generales que lo justifican. Porque la que amenaza al Estado es una sociedad compleja que dista mucho de la sociedad civil de la que hablaran Adam Smith y los fisiócratas. La de hoy es una sociedad segmentada, pluricéntrica, que parece desandar el camino de las comunidades que percibiera Ferdinand Tönnies en el inicio de la sociología moderna. Una sociedad global que obedece a intereses estrictamente egoístas y desconoce por completo las finalidades de la justicia social y de la solidaridad que inspiraron la formación del Estado social.

Es la realidad de la articulación y desarrollo de los mercados financieros la que otorga, sin ninguna atribución formal o normativa, el poder fáctico y decisorio que ostentan las grandes corporaciones mercantiles y los agentes financieros que sacralizan su interés en el beneficio inmediato en lo que Vandana Shiva ha llamado la "economía de la codicia y la globalización", y otros califican más gráficamente como "el casino global" o como "el Las Vegas" de la globalización.

El repliegue estratégico del Estado para ocupar otras posiciones desde las que pueda ejercer un poder racional y efectivo acorde a la realidad de los tiempos parece, pues, una tarea ineludible. La clave de esa recomposición es la recuperación del concepto y de la doctrina tomista del bien común, que no identifica a éste con la suma de los intereses particulares sino que es un bien cualitativamente distinto, pues es el bien del conjunto de la sociedad que como tal aprovecha y beneficia a cada uno de los miembros que la componen. La doctrina española del Derecho público conoce muy bien la significación del concepto jurídico del "interés general" que plasma el artículo 103.1 de la Constitución y que se identifica con esa doctrina del bien común, pues el interés general no es la suma de los intereses particulares de los ciudadanos, sino la consecución de un interés trascendente: el que beneficia a la sociedad en su conjunto, aunque ello implique el sacrificio de los intereses de unos frente a los de otros, especialmente los de los más desfavorecidos.

Es en esa definición y defensa del bien común, del interés general, donde encuentra su principal sentido el Estado que está perdiendo buena parte de su capacidad de gestión y acción directa, por falta de conocimiento y falta de instrumentos, ante 
una sociedad que se ha hecho poderosa a través de cerrados sistemas eficazmente organizados y autorregulados. Aquí sitúa el profesor Esteve la orientación del movimiento de repliegue estratégico y, con él, la redefinición del Estado, que -a su juicio- no puede definirse y caracterizarse ya como un Estado gestor o prestador directo de todos los servicios sociales, pues le faltan los medios y las posiciones de dominio, sino como un Estado que se concentra en los fines, en los objetivos de interés general y atención al bien común que tiene encomendados y en garantizar su realización. Es lo que se ha dado en llamar el "Estado garante", aunque hay también otros modelos novedosos que se presentan con similar cometido y con una variación fundamentalmente terminológica: otras denominaciones que vienen a expresar la misma idea; así la del "Estado regulador", que pretende regular y orientar hacia objetivos de general interés la actividad de operadores privados que ocupan los espacios de aquél en sectores clave como son los servicios públicos y los de interés general, o la muy expresiva y reciente denominación del "Estado estratega".

Y es aquí donde se sitúa la clave, a nuestro juicio, de la recomposición del Estado social.

\subsection{Claves para fijar un "mínimo social irrenunciable"}

Parece, así, que lo primero que hemos de identificar son los fines y objetivos cuya consecución ha de garantizar el Estado. Una tarea aparentemente sencilla, pues, en lo fundamental, son los que marca la Constitución y en nuestro caso los propios de un Estado social y democrático de Derecho (art. 1.1). Obviamente son los fines y objetivos del Estado social los que más amenazados se ven, los más difíciles de garantizar en un entorno de crisis económica que afecta muy directamente a las finanzas públicas. Pero son objetivos a los que no se puede renunciar: primero, porque se trata de inequívocos mandatos constitucionales enunciados como "principios rectores de la política social y económica"; y segundo, porque más allá de su enunciado literal se trata de preceptos vividos, realizados, de los que se tiene plena experiencia en la sociedad. Y es que el Estado social no ha sido una utopía como tantas que se han sucedido desde el siglo XIX. Aunque la relativa brevedad de esta experiencia, que alcanza a poco más de una generación, tal vez nos muestra ahora lo difícil que es seguir pagando su factura. En cualquier caso, ha sido y es un logro de la civilización occidental ese Estado que sobre la base de la solidaridad ha podido ofrecer cobertura asistencial al conjunto de la sociedad. Desmantelarlo sería sin duda un retroceso histórico. 
El segundo problema que ha de resolverse, mucho más difícil desde luego, es cómo se garantizan estos objetivos del Estado social, cómo se cumplen esos mandatos constitucionales sin la acción gestora y prestadora del Estado o una vez reducida ésta en razón de los objetivos de déficit.

Lo primero que ha de tenerse en cuenta, como ha notado Antonio Porras Nadales en el estudio que figura en la páginas de este número de la Revista, es que no todos los derechos sociales dependen de una clave financiera, lo que señala con acierto la existencia de límites objetivos al discurso economicista. Por tanto, hay derechos sociales que no conllevan gasto alguno para el aparato del Estado más allá del funcionamiento ordinario de las estructuras administrativas (valgan como ejemplo de ello las políticas de igualdad de género), y cuya preservación no debería estar amenazada por la reducción presupuestaria.

Incluso más allá de esta clave, hay que abandonar la creencia de que la delimitación, contenido y alcance de la acción conducente a hacer efectivos los derechos sociales está vinculada esencialmente a la coyuntura económica, de forma que pueda prescindirse de ella o reducirse su contenido prestacional en tiempos de crisis. Esta creencia no se ajusta a los valores y principios que consagra nuestra Constitución, porque la eliminación o reducción de las políticas sociales puede afectar directamente a la dignidad humana, que es un valor central situado en el artículo 10.1 de la CE ("La dignidad de la persona, los derechos inviolables que le son inherentes, el libre desarrollo de la personalidad, el respeto a la ley y a los derechos de los demás son fundamento del orden político y de la paz social") y a la igualdad material que consagra el artículo 9.2 ("Corresponde a los poderes públicos promover las condiciones para que la libertad y la igualdad del individuo y de los grupos en que se integra sean reales y efectivas; remover los obstáculos que impidan o dificulten su plenitud y facilitar la participación de todos los ciudadanos en la vida política, económica, cultural y social") y a la consecución de una convivencia más justa y solidaria.

El diseño de una nueva estrategia para la prestación de los servicios y prestaciones sociales, acompañados de sus correspondientes previsiones presupuestarias y dotados de mecanismos de garantía, de evaluación y de control tendría que tener en cuenta un criterio de prioridades. Es decir, si no es posible atender todos los derechos sociales que cuentan con reconocimiento legal y respecto de los que el legislador establece alguna acción positiva de los poderes públicos, la cota de la prestación, el límite al que debe llegar esa acción no puede depender de datos coyunturales como la existencia o no de una partida presupuestaria habilitante, del momento en que se solicita la prestación o de cualquiera otra circunstancia 
coyuntural. Es preciso fijar de antemano y de forma planificada, y en ello radica en suma el debate sobre los niveles de cobertura de las prestaciones sociales, un rango o jerarquía entre la pluralidad de derechos sociales atendibles.

Como recientemente ha apuntado el profesor Muñoz Machado en su opúsculo sobre La pobreza y el Derecho"l -que evoca el Tratado del socorro de los pobres de Luis Vives- no son iguales ni valen igual unos derechos que otros. Existe una prelación entre ellos y, por tanto, debe ser posible establecer una jerarquía de prioridades en un doble plano. En primer lugar, entre derechos sociales de diversa naturaleza entre sí: por ejemplo, no parece difícil convenir que el gasto en sanidad y en educación obligatoria es prioritario respecto del gasto en las prestaciones que dan acceso al ocio. Pero en segundo lugar, también es posible establecer una jerarquía entre las prestaciones que integran un mismo derecho o un conjunto de derechos de una misma naturaleza. Por ejemplo, en el campo de la educación no debe tener la misma prioridad la prestación de un servicio gratito de educación obligatoria de carácter universal que la gratuidad de una prestación aislada, como puedan ser los libros de texto o la universalidad del sistema de becas en razón de la renta, sin consideración de los principio de mérito y capacidad.

Es claro que lo difícil de esta operación de jerarquización es afinar con el conjunto de prioridades, pero tampoco puede negarse que existen algunas claves jurídicas para ello. Una primera clave cualitativa es -como ha quedado dicho- que el derecho social en cuestión forme o no parte de los "principios rectores de la política social y económica" que contiene el Capítulo III del Título I de la Constitución, que pueden considerarse el programa mínimo de realización del Estado social y democrático de Derecho que enuncia su artículo $1^{\circ}$.

La otra clave que debería manejarse en este debate de la ordenación de los derechos sociales en razón de lo prioritario de su atención o consecución son los dos principios constitucionales que están en la base del modelo del Estado social constitucional y que han de servirnos de guía para responder a la pregunta de qué derechos sociales atender y para qué colectivos hacerlo: los principios de dignidad que consagra el artículo 10.1 de la Constitución y de igualdad material que consagra el artículo 9.2, anteriormente transcritos.

${ }^{11}$ Que es su discurso de investidura como doctor honoris causa por la Universidad de Valencia, leído el 7 de marzo de 2013 en el Paraninfo de dicha Universidad. El texto puede consultarse en http:// www.uv.es/fatwireed/userfiles/file/Sobre\%20la\%20pobreza\%20y\%20el\%20Derecho.pdf 
El manejo y aplicación de estos criterios debería servir para ajustar en términos de sensatez y razonabilidad la dicotomía kantiana entre fines sociales con valor de "dignidad" y fines sociales con valor de "precio"; siendo los primeros que deben atenderse prioritariamente en el conjunto de los anhelos humanos. 